\title{
Public Health Control Measures for the Co-circulation of Influenza and SARS-CoV-2 During Influenza Seasons
}

\author{
John S Tam ${ }^{1,2, *} ;$ Yuelong $S^{2,3}{ }^{2,3}$
}

\section{SEASONAL INFLUENZA IN THE MIDST OF COVID-19}

The World Health Organization (WHO) named the disease caused by severe acute respiratory syndrome coronavirus 2 (SARS-CoV-2) as coronavirus disease 2019 (COVID-19) and declared the outbreak a Public Health Emergency of International Concern (PHEIC) on January 30, 2020 and a pandemic on March 11, 2020. Globally, there have been 239,437,517 confirmed cases of COVID-19 reported to WHO, including 4,879,235 (2.1\%) deaths as of October 15, 2021 (1). The COVID-19 pandemic continues to cause an unparalleled impact on global public health security and economic well-being in the context of previous influenza pandemics as well as other emerging infectious diseases in history (2). As the epidemiology, clinical presentations, and control measures for SARS-CoV-2 and influenza share many features, there is a need to develop strategies to address additional challenges arising in the continued surveillance, prevention, and clinical management of influenza in conjunction with COVID-19 pandemic responses. SARS-CoV-2 and influenza are expected to be circulating during the upcoming influenza season and may lead to situation where an amplified respiratory disease burden occurs due to both viruses spreading, causing overlapping symptoms or severe clinical illness particularly in the case of co-infections (3). Therefore, it is essential that effective public health control measures are in place for the forthcoming influenza season to protect those at risk (e.g., the elderly and patients with underlying chronic diseases), prevent severe illness, and minimize additional impact on the healthcare system and a surge in hospital admissions.

\section{EPIDEMIOLOGY OF INFLUENZA VIRUSES DURING COVID-19 PANDEMIC}

To understand the epidemiology of influenza with an ongoing circulation of SARS-CoV-2, it is essential to understand the general transmission profiles of both competing viruses. The median basic reproduction number $\left(\mathrm{R}_{0}\right)$ of seasonal influenza was estimated to be 1.28 (4). The estimated $R_{0}$ of the initial strain of SARS-CoV-2 was reported to be 2.79 (5), which explained the enhanced transmission of SARS-CoV-2 as observed during the early phase of the pandemic as compared to the transmission of seasonal influenza. The Alpha (B.1.1.7) variant of SARS-CoV-2 emerged in the United Kingdom and was the first variants of concern (VOC) to show enhanced transmissibility (43\% to $90 \%$ over the ancestral strain in UK) as well as subsequent VOCs (Beta - 50\% in South Africa; Gamma $-1.7 \%$ to $2.4 \%$ in Brazil) $(6-7)$. The Delta (B.1.617.2) variant was first detected in India and showed an estimated $\mathrm{R}_{0}$ of $5.08(8)$ and an enhanced transmission rates of $60 \%$ over that of the Alpha VOC (6). The Delta variant has replaced the other VOCs, invigorating repeated outbreaks in countries previously able to suppress COVID-19 circulation as well as resurgence of COVID-19 disease in countries with high vaccination coverage (9). The heightened transmissibility of SARS-CoV-2 will likely affect the spread of respiratory viruses and the epidemiology of influenza in the coming seasons. The differences in transmission profiles of SARS-CoV-2 and influenza may also reflect prior infection and vaccination in previous influenza seasons, conferring a level of population immunity against seasonal influenza, compared with the lack of population immunity to SARS-CoV-2.

Information from the United States (10) and several countries $(11-15)$ in the Northern Hemisphere on seasonal influenza activities during the early 2020 showed sharp declines in the number of influenza infections for the traditional high winter season for influenza. In the Southern Hemisphere, Australia, Chile, South Africa, and New Zealand reported similar observations during their influenza season in 2020 $(10,16-17)$. This phenomenon is further demonstrated using data collected on influenza surveillance in Hong 
Kong, China (Northern Hemisphere) and Australia (Southern Hemisphere) over multiple influenza seasons to October 2021. As shown in Figure 1, laboratory confirmed influenza infections for Hong Kong, China and Australia were drastically reduced during influenza seasons for 2020 and 2021. Similar finding were reported from China (18).

In addition to influenza viruses, the etiology and epidemiology of traditional infections has also been significantly altered with notable decreases in the incidence of other seasonal respiratory viral infections. With the exception of rhinoviruses (RV), the incidence of respiratory syncytial virus (RSV), parainfluenza viruses (PIV), adenovirus (AV), human metapneumovirus (hMPV), and other seasonal coronaviruses were effectively absent during surveillance activities for respiratory viruses during the COVID-19 pandemic period as reported from Australia (16), UK (15) and Canada (19).

Many studies suggested that the decline in the activities of seasonal influenza and other respiratory viruses may have been attributed to the widespread and stringent community non-pharmaceutical intervention (NPI) measures implemented to control the COVID-19 pandemic (10-11,16-17). These included the following: 1) border closure and quarantine of travelers for the control of importation; 2) community control measures such as widespread testing, isolating cases, contact tracing, and quarantine of exposed persons; 3) physical distancing measures such as stay-at-home orders, cancelling business and social gatherings, and school closures; 4) good personal and environmental hygiene including mandatory face mask policies in public areas; and 5) campaigns on risk communication to public and community stakeholders. Many of such measures implemented for COVID-19 control were also suggested to be effective for the control of influenza $(18,20-21)$. In addition to these NPI measures, promotion of influenza vaccination had also been implemented. The increase in influenza vaccine uptake for 2019/2020 and 2020/2021 season was suggested to be a major factor contributing to the reduced burden of influenza of the seasons in Hong Kong. Influenza vaccination statistics in Hong Kong demonstrated $38 \%, 26 \%, 24 \%$, and $10 \%$ increases in vaccine uptake among children aged 6 months to $<6$ years, children aged 6 to $<12$ years, adults aged 50-64 years, and the elderly aged $\geq 65$ years, respectively (22). Similar increase in influenza vaccination rates was also noted in UK for the 2020/2021 season (15).
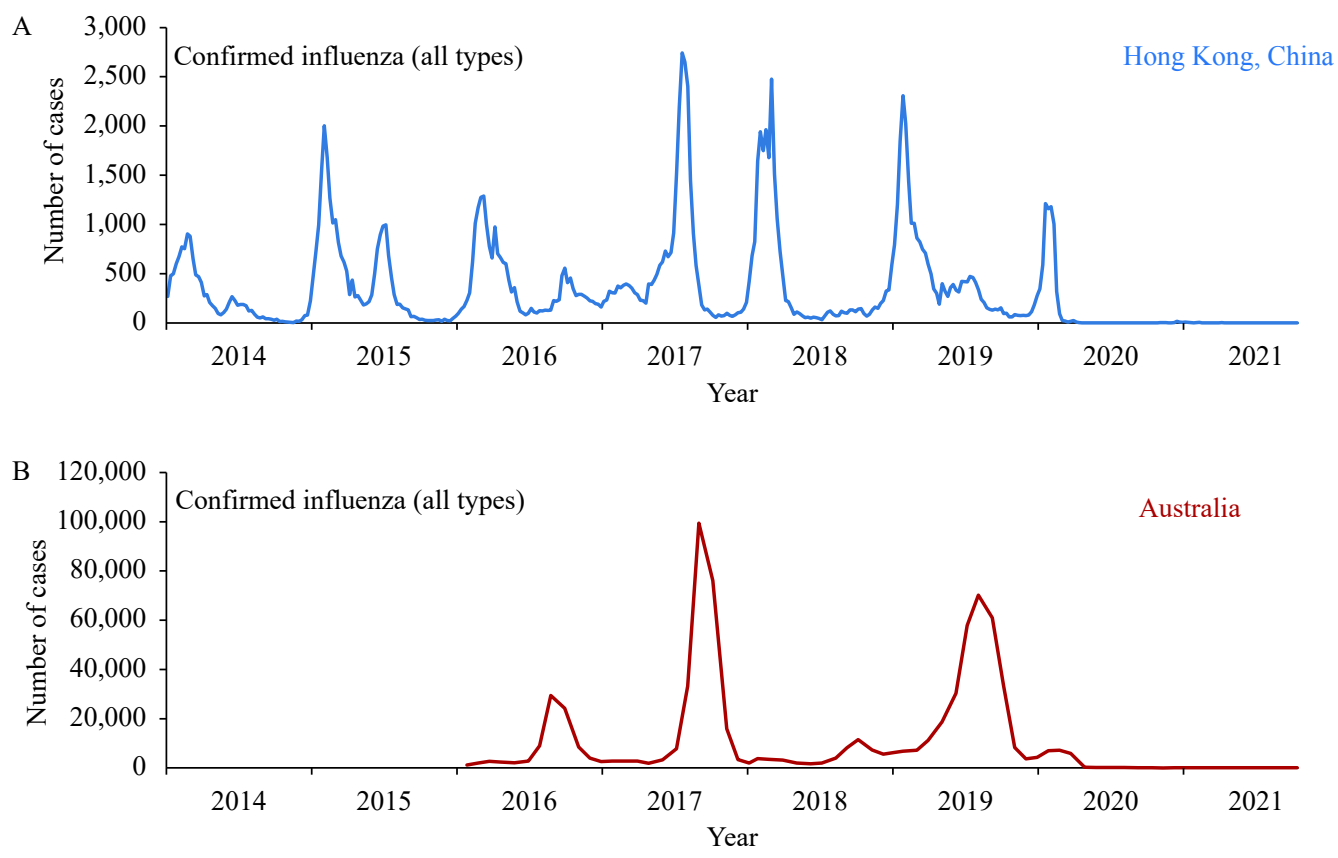

FIGURE 1. Laboratory-confirmed influenza infections in Hong Kong, China and Australia. (A) Influenza cases (January 2014-October 2021); (B) Influenza cases (January 2016-September 2021).

Notes: Figure 1A data source: Flu Express, Centre for Health Protection, Hong Kong Special Administration Region, https://www.chp.gov.hk/files/xls/flux_data.xlsx. Figure 1B data source: Immunisation Coalition, Australia, https://www.immunisationcoalition.org.au/news-data/influenza-statistics/. 


\section{INCIDENCE AND CLINICAL SIGNIFICANCE OF CO-INFECTION}

With the ongoing intense surveillance of pathogens during the COVID-19 pandemic, the recovery of other pathogens in patients with SARS-CoV-2 infection has been reported (23-25). A recent systematic review and meta-analysis on the occurrence of co-infections and superinfections and their outcomes among patients with SARS-CoV-2 infection showed that the pooled prevalence of co-infection amounts to $19 \%$ and that of superinfection was $24 \%$ in 118 publications included in the systemic review (25). Among viruses identified in the analysis, influenza A had the highest prevalence (22.3\%) followed by influenza B (3.8\%) among co-infected patients while rhinovirus was the most frequent in patients with superinfection (11\%). It is important to note from the analysis that patients identified with a co-infection or superinfection had higher odds of dying (odds ratio=3.31) than those who had SARS-CoV-2 infection alone. Patients with co-infections had a higher average length of hospital stay than those with superinfections ( 29.0 days vs. 16 days), and those with superinfections had a higher prevalence of requiring mechanical ventilation $(45 \%$ vs. $10 \%)$ than those with a co-infection. Such information stimulated many discussions about the possible impact of the coming influenza season while variants of SARS-CoV-2 are circulating at the same time (26-29).

As discussed above, influenza infection may induce severe clinical disease due to superinfection or coinfection with SARS-CoV-2 (24). Bai et al. (30) in their research provide the first experimental evidence which may explain the mechanism by which coinfection of influenza virus and SARS-CoV-2 showed enhancement in pathogenesis. It was reported that coinfection was associated with an increased expression level of ACE2, the major receptor for SARS-CoV-2 entry into target cells, leading to the augmentation of SARS-CoV-2 infectivity. It was further observed in another study that simultaneous or sequential coinfection of SARS-CoV-2 and A (H1N1)pdm09 caused more severe disease as compared to single infections by either virus in hamsters (31).

\section{CONTROL FOR CO-CIRCULATION OF SEASONAL INFLUENZA AND SARS-COV-2}

The possible impact of influenza virus and
SARS-CoV-2 co-circulating this autumn and winter season in the Northern Hemisphere has the potential to further impact the already strained public healthcare system under the COVID-19 pandemic, particularly on inpatient and intensive care utilization (32). Modeling studies on seasonal influenza implicated that as the number of seasons with low influenza activity increases, immunity in the population decreases with an increasingly susceptible population, leading to a possible $20 \%$ increase in influenza-related hospitalizations in the subsequent year if nonpharmaceutical intervention practices were eased $(29,33)$. More broadly, it is suggested that healthcare systems should fully optimize available effective strategies for influenza management in anticipating future cocirculation of influenza and SARS-CoV-2 as the 2021-2022 influenza season approaches.

\section{Diagnosis and Surveillance}

The early symptoms of COVID-19 patients often include fever, dry cough, and fatigue, and it is not possible to distinguish SARS-CoV-2 infection from those of influenza based on symptoms alone (34-35). As best practices of care for the two infections are different, making available the rapid diagnostic tests for both viruses is essential, particularly for high-risk groups and patients with severe respiratory illnesses, in the situation that co-circulation of SARS-CoV-2 and influenza viruses is anticipated. In addition, rapid diagnostic testing and surveillance are necessary to ensure effective infection control procedures, including isolation, contact tracing, quarantine of exposed individuals, and containment measures in the community or institutional/hospital settings, can be implemented swiftly.

\section{Vaccination}

Influenza vaccination of risk groups as well as healthcare workers is central in seasonal influenza control measures. The WHO and other national and international health authorities had repeatedly made influenza vaccination recommendations. However, vaccine uptake among high-risk groups and healthcare workers remained low and vaccine uptake in the elderly population remained below the WHO recommended $70 \%$ coverage even in many highincome countries (36). Additional efforts to improve influenza vaccination rates among high-risk groups and healthcare workers are an essential and effective strategy to reduce influenza burden and allow for 
better preparedness for anticipated co-circulation of influenza and SARS-CoV-2 in the coming influenza season (37). In addition, the ability of the influenza virus to augment COVID-19 severity (31) underscores the importance of influenza virus as a key target for prevention and control of severe clinical disease due to co-infection. Therefore, influenza vaccination should be recommended for populations with a high risk of co-infection.

\section{Treatment}

Influenza vaccines vary in degree of antigenic match to circulating viruses, and influenza vaccine effectiveness can differ by age group as well as the degree of antigenic match between vaccine and circulating viruses (38). A number of neuraminidase inhibitors (NAIs) such as oseltamivir as well as inhibitors targeting the viral polymerase such as baloxavir, had been evaluated and demonstrated to be effective for the prophylaxis and treatment of influenza (39-40). However, no antiviral has been approved for the treatment of SARS-CoV-2 infection to date. In anticipation of cocirculation of influenza and SARS$\mathrm{CoV}-2$, strategies on influenza antiviral use should be developed to provide high-risk individuals with antivirals prophylactically and patients are treated within the 48-hour window according to established treatment guidelines. Prophylactic use of influenza antivirals may also be warranted during influenza outbreaks in care homes or institutions as an additional protective measure to reduce influenza burden and burden of co-infection in the most vulnerable populations.

\section{CONCLUSION}

The emergence of SARS-CoV-2 has resulted in an unprecedented global pandemic causing substantial morbidity and mortality, particularly among older and vulnerable adult populations. Public health policymakers worldwide have instituted stringent nonpharmaceutical interventions to mitigate the transmission of SARS-CoV-2 virus. Vaccines for SARS-CoV-2 have been developed and global vaccination for high-risk populations has been implemented gradually. There was concern regarding the potential of increased healthcare burden from the dual impact of an ongoing COVID-19 pandemic coinciding with the seasonal influenza virus peak which may cause significant additional morbidity, mortality, and health-service demand. Experimental and surveillance reports also indicated that co-infection with influenza viruses and SARS-CoV-2 occurs with enhanced severity. As the 2021-2022 NorthernHemisphere influenza season approaches, it is important to maintain a high index of suspicion for coinfection. Measures should be adopted to prevent coinfection. Vaccination against influenza becomes even more important. Rapid diagnostic evaluation of patients presenting in respiratory distress to emergency departments for both SARS-CoV-2 and influenza is necessary. Treatment with antiviral agents for influenza should be initiated. Moreover, social distancing and mask wearing are beneficial to protect people from the transmission of either or both viruses.

doi: $10.46234 / \mathrm{ccdcw} 2021.228$

\# Corresponding author: John S Tam, john.sl.tam@polyu.edu.hk.

\footnotetext{
${ }^{1}$ Department of Applied Biology and Chemical Technology, Hong Kong Polytechnic University, Hong Kong, China; ${ }^{2}$ Asia Pacific Alliance for the Control of Influenza (APACI), South Melbourne, VIC, Australia; ${ }^{3}$ School of Public Health (Shenzhen), Sun Yat-sen University, Guangzhou, Guangdong, China.
}

Submitted: October 25, 2021; Accepted: October 28, 2021

\section{REFERENCES}

1. World Health Organization. WHO Coronavirus (COVID-19) Dashboard. 2021. https://covid19.who.int/. [2021-10-17].

2. Shang YF, Li HW, Zhang R. Effects of pandemic outbreak on economies: evidence from business history context. Front Public Health 2021;9:632043. http://dx.doi.org/10.3389/fpubh.2021.632043.

3. Ma SM, Lai XQ, Chen Z, Tu SH, Qin K. Clinical characteristics of critically ill patients co-infected with SARS-CoV-2 and the influenza virus in Wuhan, China. Int J Infect Dis 2020;96:683 - 7. http://dx.doi. org/http://dx.doi.org/10.1016/j.ijid.2020.05.068.

4. Biggerstaff M, Cauchemez S, Reed C, Gambhir M, Finelli L. Estimates of the reproduction number for seasonal, pandemic, and zoonotic influenza: a systematic review of the literature. BMC Infect Dis 2014;14(1):480. http://dx.doi.org/10.1186/1471-2334-14-480.

5. Liu Y, Gayle AA, Wilder-Smith A, Rocklöv J. The reproductive number of COVID-19 is higher compared to SARS coronavirus. J Travel Med 2020;27(2):taaa021. http://dx.doi.org/10.1093/jtm/taaa021.

6. Davies NG, Abbott S, Barnard RC, Jarvis CI, Kucharski AJ, Munday JD, et al. Estimated transmissibility and impact of SARS-CoV-2 lineage B.1.1.7 in England. Science 2021;372(6538):eabg3055. http://dx. doi.org/10.1126/science.abg3055.

7. Tian DD, Sun YH, Zhou JM, Ye Q. The global epidemic of SARS$\mathrm{CoV}-2$ variants and their mutational immune escape. J Med Virol 20211 - 11. http://dx.doi.org/10.1002/jmv.27376.

8. Liu Y, Rocklöv J. The reproductive number of the Delta variant of SARS-CoV-2 is far higher compared to the ancestral SARS-CoV-2 virus. J Travel Med 2021;28(7):taab124. http://dx.doi.org/10.1093/ $\mathrm{jtm} / \mathrm{taab} 124$

9. Lechien JR, Saussez S. Importance of epidemiological factors in the evaluation of transmissibility and clinical severity of SARS-CoV-2 variants. Lancet Infect Dis 2021. http://dx.doi.org/10.1016/S14733099(21)00474-6.

10. Olsen SJ, Azziz-Baumgartner E, Budd AP, Brammer L, Sullivan S, 
Pineda RF, et al. Decreased influenza activity during the covid-19 pandemic-United States, Australia, Chile, and South Africa, 2020. Morb Mortal Wkly Rep 2020;69(37):1305 - 9. http://dx.doi.org/10. 15585/mmwr.mm6937a6.

11. Soo RJJ, Chiew CJ, Ma S, Pung R, Lee V. Decreased influenza incidence under COVID-19 control measures, Singapore. Emerg Infect Dis 2020;26(8):1933 - 5. http://dx.doi.org/10.3201/eid2608.201229.

12. Suntronwong N, Thongpan I, Chuchaona W, Lestari FB, Vichaiwattana P, Yorsaeng R, et al. Impact of COVID-19 public health interventions on influenza incidence in Thailand. Pathog Glob Health 2020;114(5):225 - $7 . \quad$ http://dx.doi.org/10.1080/20477724.2020.17 77803.

13. Lei $\mathrm{H}, \mathrm{Xu} \mathrm{MD}$, Wang $\mathrm{X}$, Xie $\mathrm{Y}, \mathrm{Du} \mathrm{XJ}$, Chen $\mathrm{T}$, et al. Nonpharmaceutical interventions used to control COVID-19 reduced seasonal influenza transmission in China. J Infect Dis 2020; 222(11):1780 - 3. http://dx.doi.org/10.1093/infdis/jiaa570.

14. Kuo SC, Shih SM, Chien LH, Hsiung CA. Collateral benefit of COVID-19 control measures on influenza activity, Taiwan. Emerg Infect Dis 2020;26(8):1928 - 30. http://dx.doi.org/10.3201/eid2608. 201192.

15. Public Health England. Surveillance of influenza and other seasonal respiratory viruses in the UK Winter 2020 to 2021. 2021. https://assets. publishing.service.gov.uk/government/uploads/system/uploads/ attachment_data/file/995284/Surveillance_of_influenza_and_other_ seasonal_respiratory_viruses_in_the_UK_2020_to_2021-1.pdf. [202110-2].

16. Sullivan SG, Carlson S, Cheng AC, Chilver MBN, Dwyer DE, Irwin $\mathrm{M}$, et al. Where has all the influenza gone? The impact of COVID-19 on the circulation of influenza and other respiratory viruses, Australia, March to September 2020. Eurosurveillance 2020;25(47):2001847. http://dx.doi.org/10.2807/1560-7917.ES.2020.25.47.2001847.

17. Huang QS, Wood T, Jelley L, Jennings T, Jefferies S, Daniells K, et al. Impact of the COVID-19 nonpharmaceutical interventions on influenza and other respiratory viral infections in New Zealand. Nat Commun 2021;12(1):1001. http://dx.doi.org/10.1038/s41467-02121157-9.

18. Feng LZ, Zhang T, Wang Q, Xie YR, Peng ZB, Zheng JD, et al. Impact of COVID-19 outbreaks and interventions on influenza in China and the United States. Nat Commun 2021;12(1):3249. http:// dx.doi.org/10.1038/s41467-021-23440-1.

19. Groves HE, Piché-Renaud PP, Peci A, Farrar DS, Buckrell S, Bancej C, et al. The impact of the COVID-19 pandemic on influenza, respiratory syncytial virus, and other seasonal respiratory virus circulation in Canada: a population-based study. Lancet Reg Health - Am 2021;1:100015. http://dx.doi.org/10.1016/j.lana.2021.100015.

20. Aledort JE, Lurie N, Wasserman J, Bozzette SA. Non-pharmaceutical public health interventions for pandemic influenza: an evaluation of the evidence base. BMC Public Health 2007;7(1):208. http://dx.doi.org/ 10.1186/1471-2458-7-208.

21. Cowling BJ, Ali ST, Ng TWY, Tsang TK, Li JCM, Fong MW, et al. Impact assessment of non-pharmaceutical interventions against coronavirus disease 2019 and influenza in Hong Kong: an observational study. Lancet Public Health 2020;5(5):E279 - 88. http://dx.doi.org/ 10.1016/S2468-2667(20)30090-6.

22. You JHS. Impact of COVID-19 infection control measures on influenza-related outcomes in Hong Kong. Pathog Glob Health 2021;115(2):93 - 9. http://dx.doi.org/10.1080/20477724.2020.1857 492.

23. Dadashi M, Khaleghnejad S, Elkhichi PA, Goudarzi M, Goudarzi H, Taghavi A, et al. COVID-19 and influenza Co-infection: a systematic review and meta-analysis. Front Med 2021;8:681469. http://dx. doi.org/10.3389/fmed.2021.681469.

24. Alosaimi B, Naeem A, Hamed ME, Alkadi HS, Alanazi T, Al Rehily SS, et al. Influenza co-infection associated with severity and mortality in COVID-19 patients. Virol J 2021;18(1):127. http://dx.doi.org/ 10.1186/s12985-021-01594-0.

25. Musuuza JS, Watson L, Parmasad V, Putman-Buehler N, Christensen L, Safdar N. Prevalence and outcomes of co-infection and superinfection with SARS-CoV-2 and other pathogens: a systematic review and meta-analysis. PLoS One 2021;16(5):e0251170. http://dx. doi.org/10.1371/journal.pone.0251170.

26. Covin S, Rutherford GW. Coinfection, severe acute respiratory syndrome coronavirus 2 (SARS-CoV-2), and influenza: an evolving puzzle. Clin Infect Dis 2021;72(12):e993 - 4. http://dx.doi.org/ $10.1093 / \mathrm{cid} /$ ciaal 1810 .

27. Iacobucci G. Covid-19: risk of death more than doubled in people who also had flu, English data show. BMJ 2020;370:m3720. http://dx.doi. org/10.1136/bmj.m3720.

28. Rubin R. What happens when COVID-19 collides with flu season? JAMA 2020;324(10):923 - 5. http://dx.doi.org/10.1001/jama.2020. 15260.

29. Lee K, Jalal H, Raviotta JM, Krauland MG, Zimmerman RK, Burke DS, et al. Predicting the impact of low influenza activity in 2020 on population immunity and future influenza season in the United States. medRxiv 2021. http://dx.doi.org/10.1101/2021.08.29.21262803.

30. Bai L, Zhao YL, Dong JZ, Liang SM, Guo M, Liu XJ, et al. Coinfection with influenza a virus enhances SARS-CoV-2 infectivity. Cell Res 2021;31(4):395 - 403. http://dx.doi.org/10.1038/s41422021-00473-1.

31. Zhang AJ, Lee ACY, Chan JFW, Liu FF, Li C, Chen YX, et al. Coinfection by severe acute respiratory syndrome coronavirus 2 and influenza $\mathrm{A}(\mathrm{H} 1 \mathrm{~N} 1) \mathrm{pdm} 09$ virus enhances the severity of pneumonia in golden Syrian hamsters. Clin Infect Dis 2021;72(12):e978 - 92. http:// dx.doi.org/10.1093/cid/ciaa1747..

32. Belongia EA, Osterholm MT. COVID-19 and flu, a perfect storm. Science 2020;368(6496):1163. http://dx.doi.org/10.1126/science. abd2220.

33. Baker RE, Park SW, Yang WC, Vecchi GA, Metcalf CJE, Grenfell BT. The impact of COVID-19 nonpharmaceutical interventions on the future dynamics of endemic infections. Proc Natl Acad Sci USA 2020;117(48):30547 - 53. http://dx.doi.org/10.1073/pnas.20131 82117.

34. World Health Organization. Coronavirus disease (COVID-19): similarities and differences between COVID-19 and influenza 2020. https://www.who.int/emergencies/diseases/novel-coronavirus-2019/ question-and-answers-hub/q-a-detail/q-a-similarities-and-differencescovid-19-and-influenza. [2021-8-20].

35. Zhou XL, Ding GY, Shu T, Fu SZ, Tong WW, Tu XP, et al. The outbreak of coronavirus disease 2019 interfered with influenza in Wuhan. SSRN Journal 2020. http://dx.doi.org/10.2139/ssrn. 3555239 .

36. Organisation for Economic Co-operation and Development. Influenza vaccination rates. 2020. https://data.oecd.org/healthcare/influenzavaccination-rates.htm. [2021-8-20].

37. The Academy of Medical Sciences. Preparing for a challenging winter 2020/21. 2020. https://acmedsci.ac.uk/file-download/51353957. [2021-9-10].

38. World Health Organization. Evaluation of influenza vaccine effectiveness: a guide to the design and interpretation of observational studies.2017.https://apps.who.int/iris/bitstream/handle/10665/255203/ 9789241512121-eng.pdf. [2021-9-20].

39. Wang CB, Chiu ML, Lin PC, Liang WM, Chen CY, Chang YJ, et al. Prompt oseltamivir therapy reduces medical care and mortality for patients with influenza infection: an Asian population cohort study. Medicine 2015;94(27):e1070. http://dx.doi.org/10.1097/MD.000000 0000001070.

40. Hayden FG, Sugaya N, Hirotsu N, Lee N, De Jong MD, Hurt AC, et al. Baloxavir marboxil for uncomplicated influenza in adults and adolescents. N Engl J Med 2018;379(10):913-23. http://dx. doi.org/10.1056/NEJMoa1716197. 